(C) Elsevier Sequoia S.A., Lausanne - Printed in The Netherlands

\title{
CAVITATION EROSION IN VIBRATORY AND VENTURI FACILITIES
}

\author{
T. OKADA* and F. G. HAMMITT
}

Department of Mechanical Engineering, Cavitation and Multiphase Flow Laboratory, University of Michigan, Ann Arbor, MI 48109 (U.S.A.)

(Received June 2, 1980)

\section{Summary}

Water cavitation erosion results from Venturi and vibratory tests of fully annealed commercially pure aluminum and annealed carbon steel are compared to obtain a better understanding of the mechanisms involved in these static and flowing tests. Significant differences between the initial pit characteristics were found, which were due primarily to the different bubble sizes and collapse pressures. The ratio of erosion rates from the two facilities was larger for the weaker material (aluminum). Results were also compared with pulse height spectra from individual bubble collapse in the Venturi tests.

\section{Introduction}

Venturi facilities as well as vibratory facilities are often used as laboratory research tools for cavitation erosion. Results in a Venturi facility are similar to cavitation erosion results in hydraulic machinery. However, the erosion rate in such tests is often very small, and test times are long compared with the higher intensity tests provided by vibratory facilities. This is due to the differences between the facilities concerning the inception and collapse of bubbles. If we compare both types of facility at the University of Michigan (Table 1), the bubbles in the vibratory facility collapse without moving from the place where they were produced but the bubbles in the Venturi facility are moved about $46 \mathrm{~mm}$ by the liquid velocity from the point of inception to collapse. The elapsed time from inception to collapse is about 20 times greater in the Venturi than in the vibratory facility. Hence the mean bubble size is presumably larger in the Venturi tests.

In the Venturi test, although weight loss by cavitation erosion is small, much larger particles were produced [1] than were observed in vibratory tests. It is thus concluded that there is some difference between the cavitation erosion mechanisms of these facilities. In the present paper, exper-

\footnotetext{
*On leave from Mechanical Engineering Department, Fukui University, Fukui, Japan.
} 
TABLE 1

Comparison of the dimensions of Venturi and vibratory facilities

\begin{tabular}{|c|c|c|c|}
\hline & \multicolumn{2}{|l|}{ Vibratory facility ${ }^{a}$} & \multirow[t]{2}{*}{ Venturi facility } \\
\hline & $\begin{array}{l}\text { Double amplitude, } \\
10^{-3} \text { in }(25.4 \mu \mathrm{m})\end{array}$ & $\begin{array}{l}\text { Double amplitude, } \\
2 \times 10^{-3} \text { in } \\
(50.8 \mu \mathrm{m})\end{array}$ & \\
\hline Flow velocity & 20 in s $^{-1}\left(0.5 \mathrm{~m} \mathrm{~s}^{-1}\right)$ & 40 in s $\mathrm{s}^{-1}\left(1 \mathrm{~m} \mathrm{~s}^{-1}\right)$ & $\begin{array}{l}161 \mathrm{ft} \mathrm{s}^{-1} \\
\left(49 \mathrm{~m} \mathrm{~s}^{-1}\right)\end{array}$ \\
\hline $\begin{array}{l}\text { Distance from bubble } \\
\text { inception to collapse }\end{array}$ & $\approx 0$ in & $\approx 0$ in & $1.79 \mathrm{in}(45.5 \mathrm{~mm})$ \\
\hline Duration of bubble growth & $50 \mu \mathrm{s}$ & $50 \mu \mathrm{s}$ & $1000 \mu \mathrm{s}$ \\
\hline
\end{tabular}

Frequency, $20 \mathrm{kHz}$.

imental research concerning cavitation erosion mechanisms for both facilities is reported based on new results and on our numerous previous investigations at both the University of Michigan and Fukui University.

\section{Experimental procedure}

\subsection{Test specimens}

The test specimens for the vibratory and Venturi erosion tests are shown in Fig. 1. The materials used for the present tests were 1018 carbon steel and 1100-0 Al. The heat treatments before and after machining, the surface finishes and the hardnesses of the test pieces are listed in Table 2. This work, and the specimen fabrication, was carried out in the laboratories of Fukui University.

\subsection{Vibratory erosion test}

A conventional piezoelectric oscillator $(20 \mathrm{kHz})$ was used for the vibratory erosion test. The double-horn amplitudes (peak to peak) were $1.0 \times 10^{-3}, 1.5 \times 10^{-3}$ and $2.0 \times 10^{-3}$ in $(25.4,38.1$ and $50.8 \mu \mathrm{m})$ in a $1000 \mathrm{~cm}^{3}$ glass beaker with fresh water (Ann Arbor tap water) at $80^{\circ} \mathrm{F}$ $\left(26.7^{\circ} \mathrm{C}\right)$ under atmospheric pressure. The weight loss was measured with an analytical balance (sensitivity, $0.01 \mathrm{mgf}$ ), and the damaged surfaces in the early stages of cavitation erosion were observed with an optical microscope.

\subsection{Venturi erosion tests}

The cavitation erosion Venturi tests were carried out in room temperature tap water at about $25{ }^{\circ} \mathrm{C}$ in a high speed cavitation tunnel at the University of Michigan [2]. The specific Venturi geometry has a nominal 0.5 in $(12.7 \mathrm{~mm}$ ) throat (Fig. 2). The maximum flow velocity at the throat was about $49 \mathrm{~m} \mathrm{~s}^{-1}$. Two test pieces (Fig. 1(c)) were always tested together 


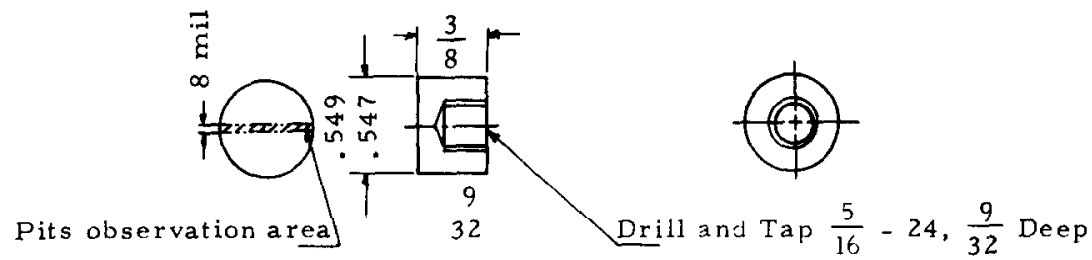

(a)

Pits observation areal

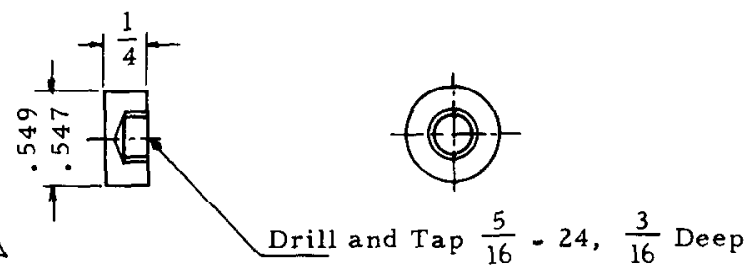

(b)

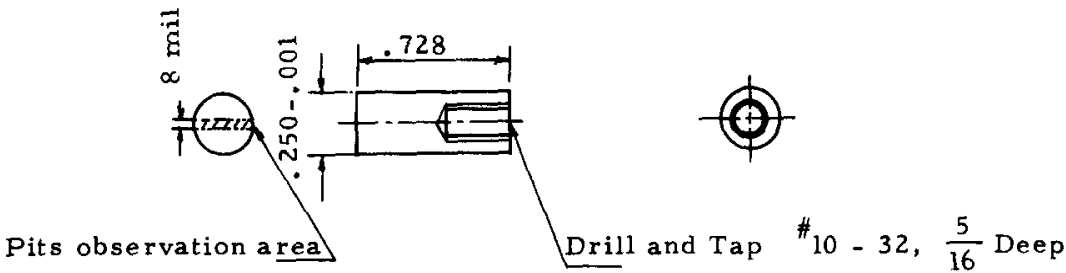

(c)

Fig. 1. Test specimens (all dimensions are in inches): (a) vibratory facility, 1100-0 Al specimen; (b) vibratory facility, 1018 carbon steel specimen; (c) Venturi facility, 1100-0 $\mathrm{Al}$ and 1018 carbon steel specimens.

\section{TABLE 2}

Heat treatments, surface finishes and hardnesses of test specimens

\begin{tabular}{|c|c|c|c|c|}
\hline \multirow[t]{2}{*}{ Material } & \multicolumn{2}{|l|}{ Heat treatment } & \multirow[t]{2}{*}{ Surface finish } & \multirow{2}{*}{$\begin{array}{l}\text { Hardness } \\
\text { (HB) }\end{array}$} \\
\hline & Before machining & After machining & & \\
\hline 1018 carbon steel & $\begin{array}{r}910^{\circ} \mathrm{C} ; 1 \mathrm{~h} ; \\
\text { normalized }\end{array}$ & $\begin{array}{l}600^{\circ} \mathrm{C} ; 30 \mathrm{~min} ; \\
\text { annealed }\end{array}$ & $\begin{array}{l}\text { Polished with } \\
1500 \text { emery } \\
\text { paper and } \\
\text { buffed with } \\
\text { diamond paste }\end{array}$ & 111 \\
\hline $1100-0 \mathrm{Al}$ & None & $\begin{array}{l}350^{\circ} \mathrm{C} ; 15 \mathrm{~min} \\
\text { annealed }\end{array}$ & As above & 41 \\
\hline
\end{tabular}

fitted in axially symmetric positions in the cavitation collapse region (Fig. 2, plane A-A). No systematic difference between test positions was found in these or in previous tests. A microtransducer located in the plane of the spec- 


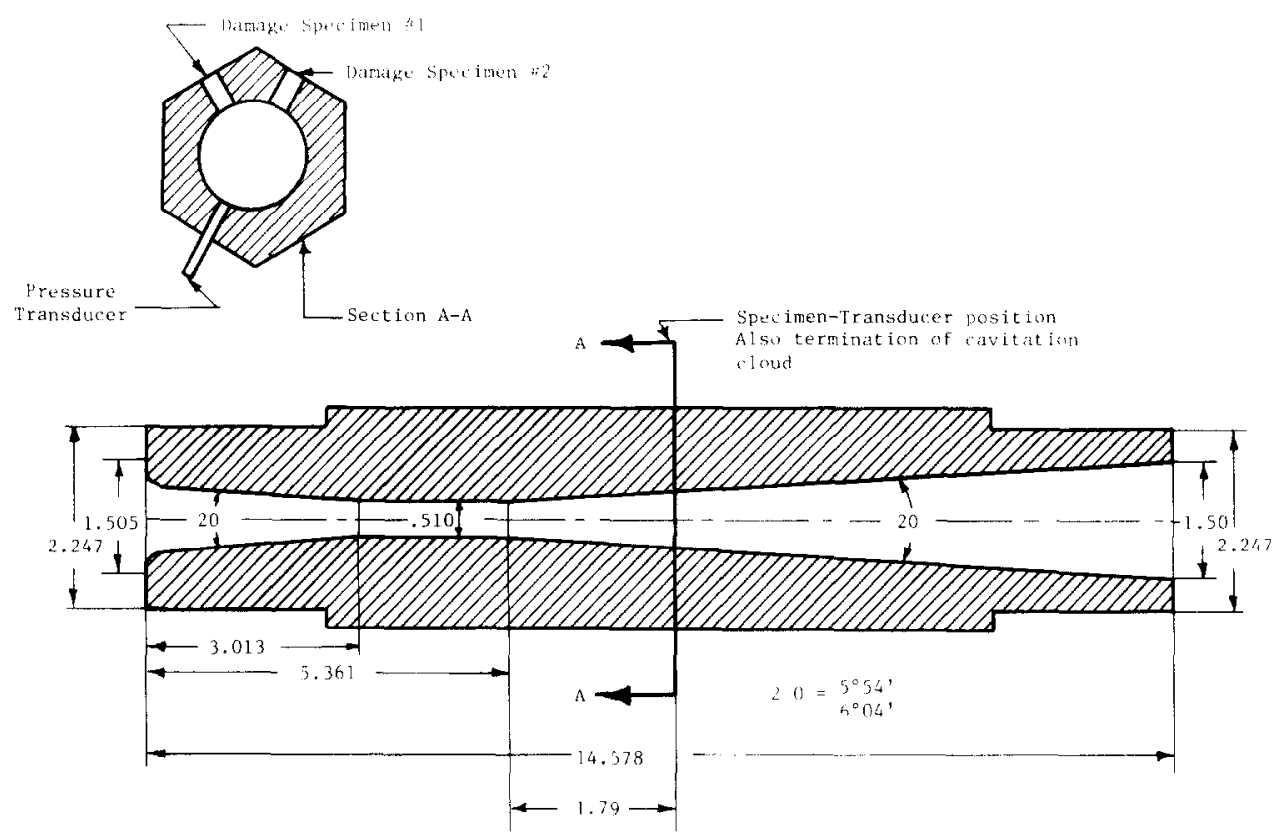

Fig. 2. Venturi dimensions (all dimensions are given in inches).

imen position was used in other tests [3] to measure bubble collapse pulse height spectra.

\section{Experimental results and discussion}

Figures 3 - 6 show vibratory weight losses and mean depth of penetration rates (MDPRs) for 1018 carbon steel and 1100-0 Al. Vibratory cavitation erosion for carbon steel, previously reported, can be divided into four stages [4] : I, an initial period; II, an incubation period; III, a transition period; IV, a stationary period which produces $M D P R_{\max }$. However, for $1100-0 \mathrm{Al}$, no initial period is found because impact fracture can hardly occur with this soft ductile material.

For 1018 carbon steel the weight loss curve at higher amplitudes crosses that at lower amplitudes in the early stages (Fig. 3). This indicates that cavitation erosion at higher amplitudes involves substantial surface hardening and rapid surface fracture under this higher cavitation intensity.

Figure 7 shows the results for 1018 carbon steel in the Venturi test. The weight loss is very small compared with that in the vibratory test even if the smaller diameter is considered, i.e. in terms of the mean depth of penetration (MDP) which is equal to the volume loss divided by the exposed area. Figure 8 shows previous $1100-0 \mathrm{Al}$ Venturi results at the University of Michigan [5]. This test was for $14 \mathrm{~h}$ at a throat velocity of $49.0 \mathrm{~m} \mathrm{~s}^{-1}$ after being tested first for $27 \mathrm{~h}$ at $36.3 \mathrm{~m} \mathrm{~s}^{-1}$. In this case an initial jump was 


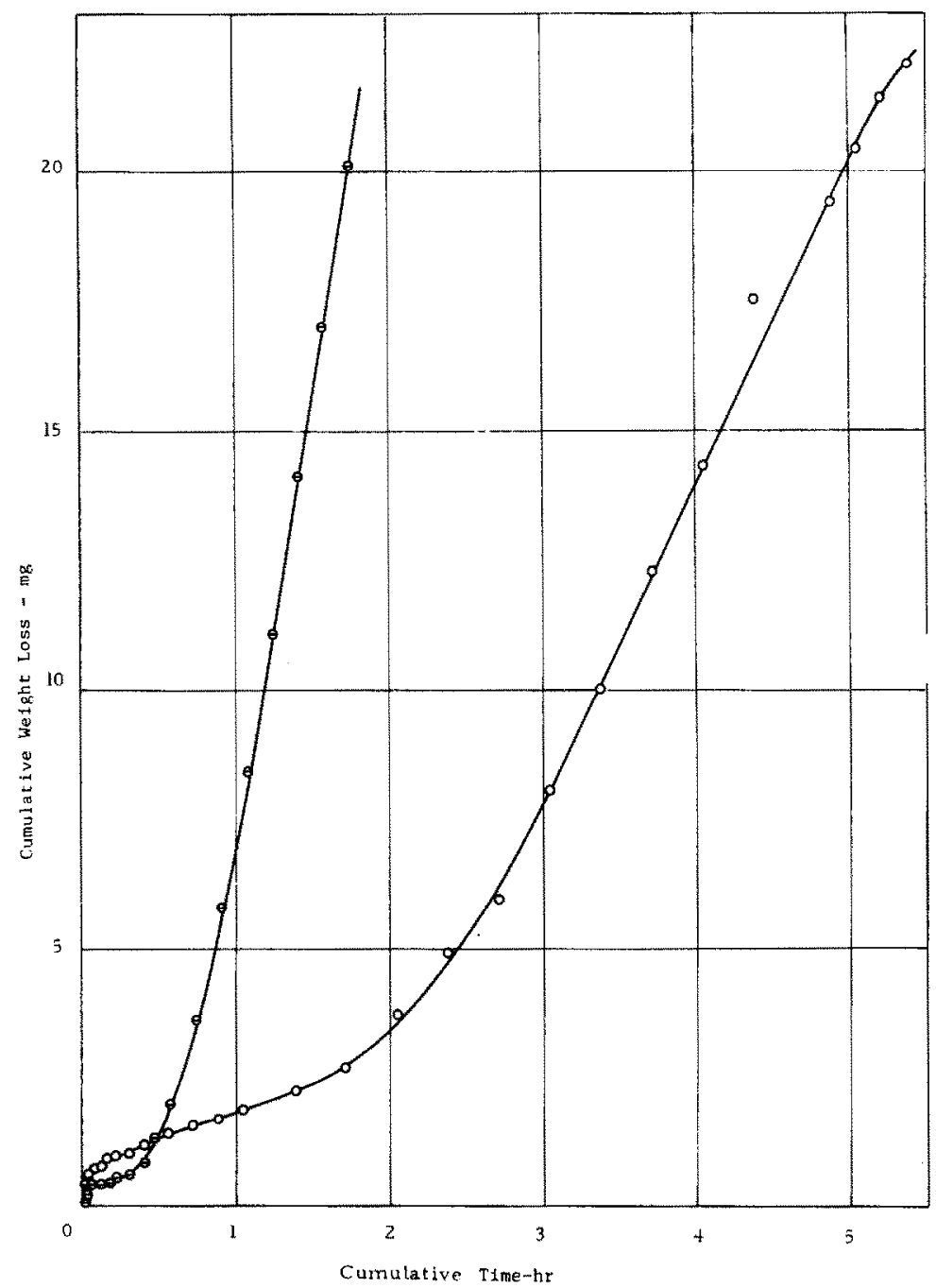

Fig. 3. Cumulative weight loss curves of 1018 carbon steel in vibratory test: $0,1.0 \times$ $10^{-3}$ in $(25.4 \mu \mathrm{m}) ; \ominus, 2.0 \times 10^{-3}$ in $(50.8 \mu \mathrm{m})$.

observed, thus differing from the vibratory test. However, the MDPR thereafter was slow compared with that in the vibratory test. MDPR $_{\max }$ results from these experiments are shown in Table 3. The difference in the $\mathrm{MDPR}_{\max }$ values of these facilities is smaller for 1018 carbon steel than for 1100-0 Al.

Cavitation intensity for both facilities can be compared in several ways: measurement of surface plastic deformation using the soft material [6]; measurement of the bubble collapse pressures directly by microtransducer [3] ; measurement of total sound intensity, e.g. as in ref. 7. In the present paper, cavitation intensities in both facilities are compared by examining the 


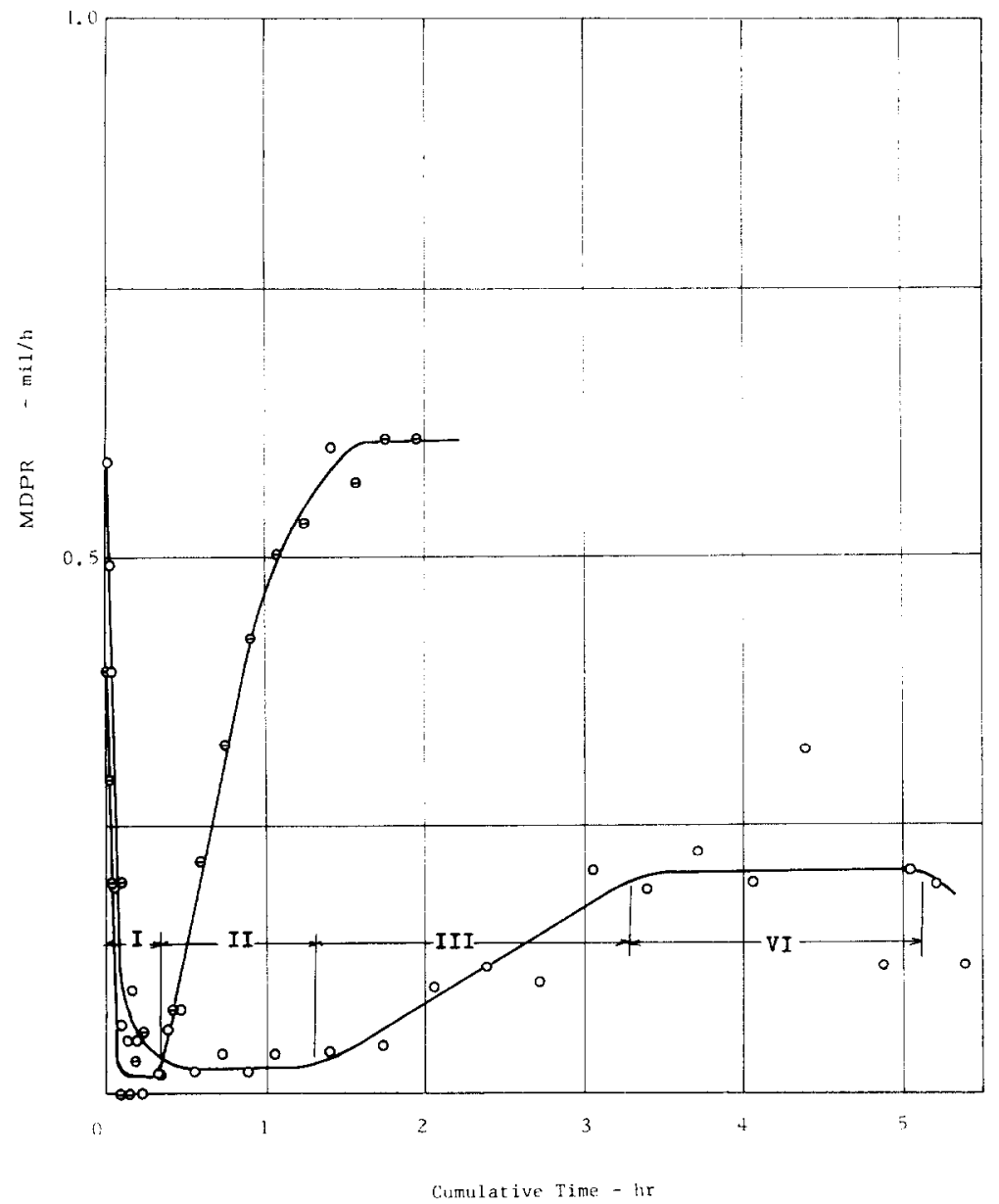

Fig. 4. MDPR curve of 1018 carbon steel in vibratory test: the symbols are as in Fig. 3.

erosion pits. Figure 9 is an example of pits observed. As reported before [8] for carbon steel, whose deformation depends on stress velocity, circular dents from which the surface material at the center is removed are formed by single-event bubble collapses. Therefore the pit size depends on the amplitude of bubble collapse pressure. The number of such pits increases linearly with exposure time [8]. However, after long exposure times the pits are hard to observe because of the spongy surface induced by the surface fatigue fractures.

Table 4 shows the sizes of pits formed on the surface of 1018 carbon steel vibratory test pieces after $15 \mathrm{~s}$, as well as those from Venturi test pieces after $30 \mathrm{~min}$, measured with an optical microscope. The observation area was $8 \times 10^{-3}$ in wide and the specimen diameter in length (Fig. 1).

It was expected that larger pits would be found on the surface of the Venturi test specimens, since larger bubbles are expected there. However, only pits smaller than those in the vibratory test were found, and the pit 


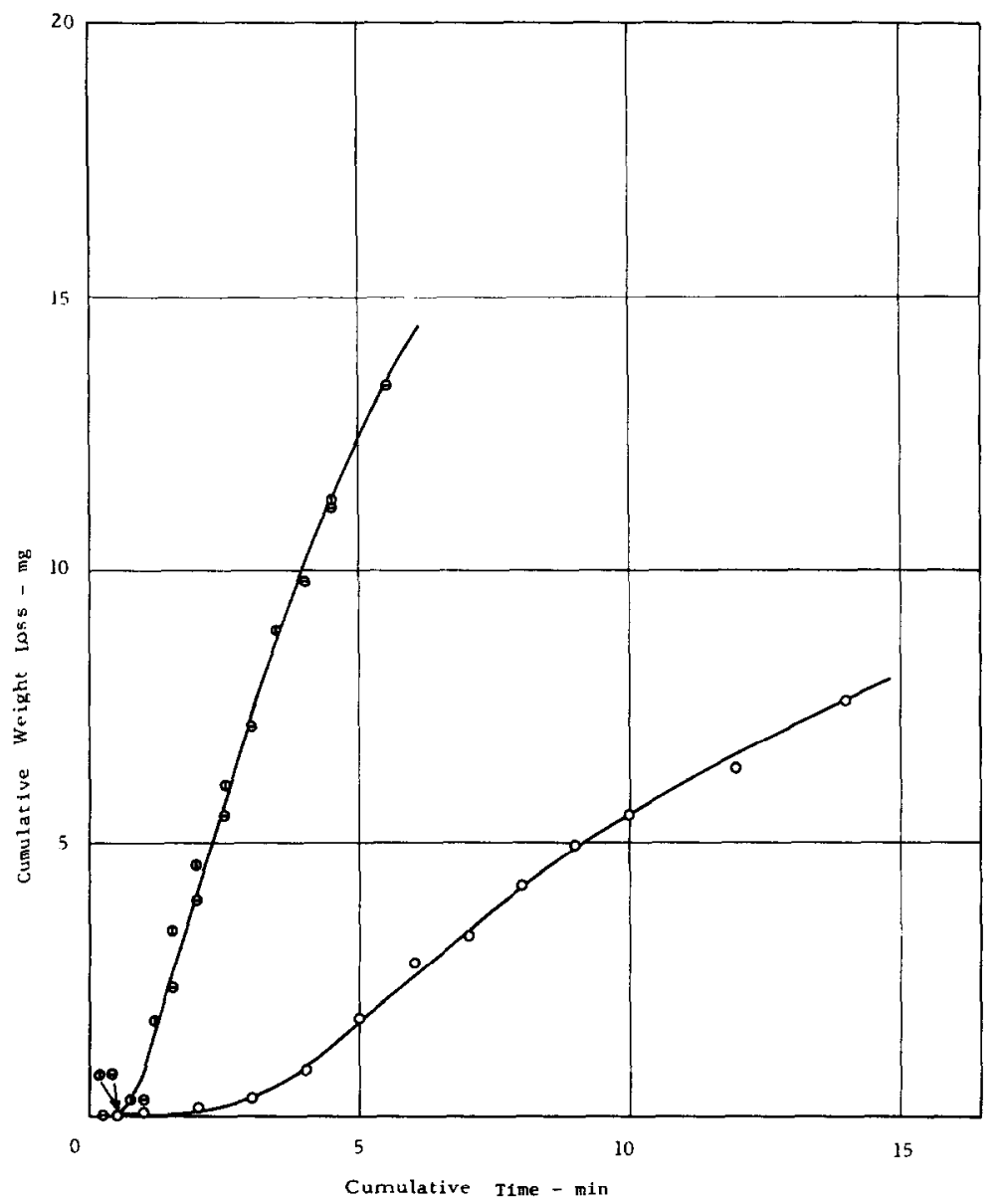

Fig. 5. Cumulative weight loss curves of $1100-0 \mathrm{Al}$ in vibratory test: $0,1.0 \times 10^{-3}$ in $(25.4 \mu \mathrm{m}) ; \ominus, \oplus, 1.5 \times 10^{-3}$ in $(37.6 \mu \mathrm{m})$.

formation rate was also much smaller. Previous work [9] with a foil-type specimen did show large pits (approximately $1 \times 10^{-3}$ in in diameter) in the same Venturi design for both carbon steel and stainless steel (type 302). It is considered that, in the vibratory test, bubbles which do not collapse in a single horn cycle may coalesce and collapse as larger bubbles. This possibility was confirmed by an earlier photographic study at the University of Michigan [10].

Figure 10 [3] shows a microtransducer bubble collapse pulse height spectrum from the same Venturi test under the same flow conditions, at the same position as the specimen. It appears that there are more smaller bubble collapse pressure impulses than the larger collapse pressures which may form individual pits on the 1018 carbon steel. Surface stresses are larger than those measured from pulses because of the relatively large probe diameter. 


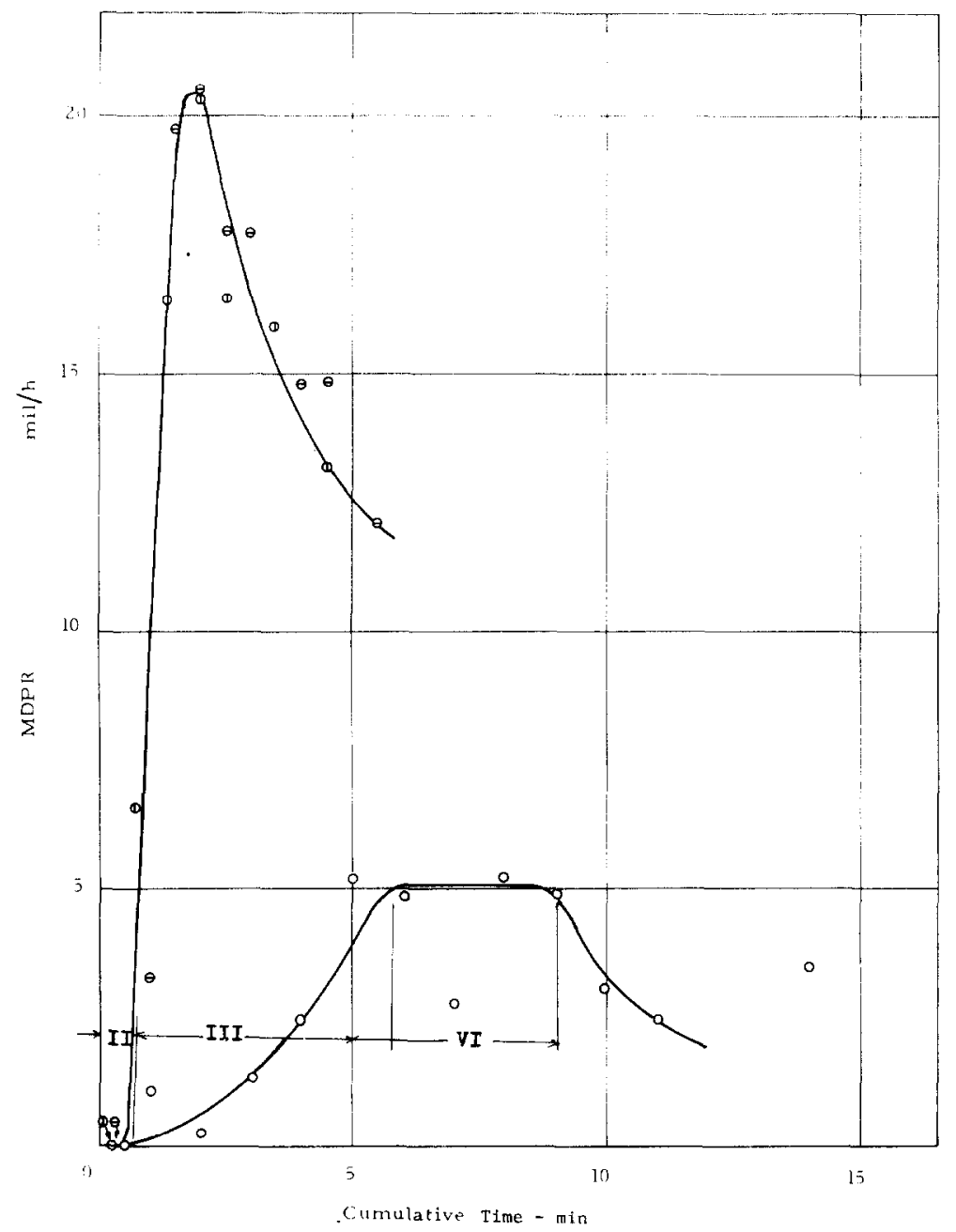

Fig. 6. MDPR curve of 1100-0 Al in vibratory test: the symbols are as in Fig. 5 .

Consequently, in the Venturi test, each bubble grows to a certain extent and collapses, providing an individual impulse. In the vibratory test, however, the bubbles which collapse [10] are generally smaller because of the high horn frequency. However, the bubbles which do not collapse in 1 cycle may coalesce and then collapse. The distribution of bubble collapse pressures is assumed to be of the same general shape (Fig. 11) in both facilities. Of course, the magnitudes no doubt differ.

In Fig. 11, $P_{1}$ is the lower critical pressure to form pits impulsively on the surface of 1018 carbon steel, $P_{2}$ is the lower critical pressure to form fatigue fracture, by repeated bubble collapse, and $P_{3}$ is the lower critical pressure for fatigue fracture from repeated bubble collapse pressure on 1100-0 Al. Then 


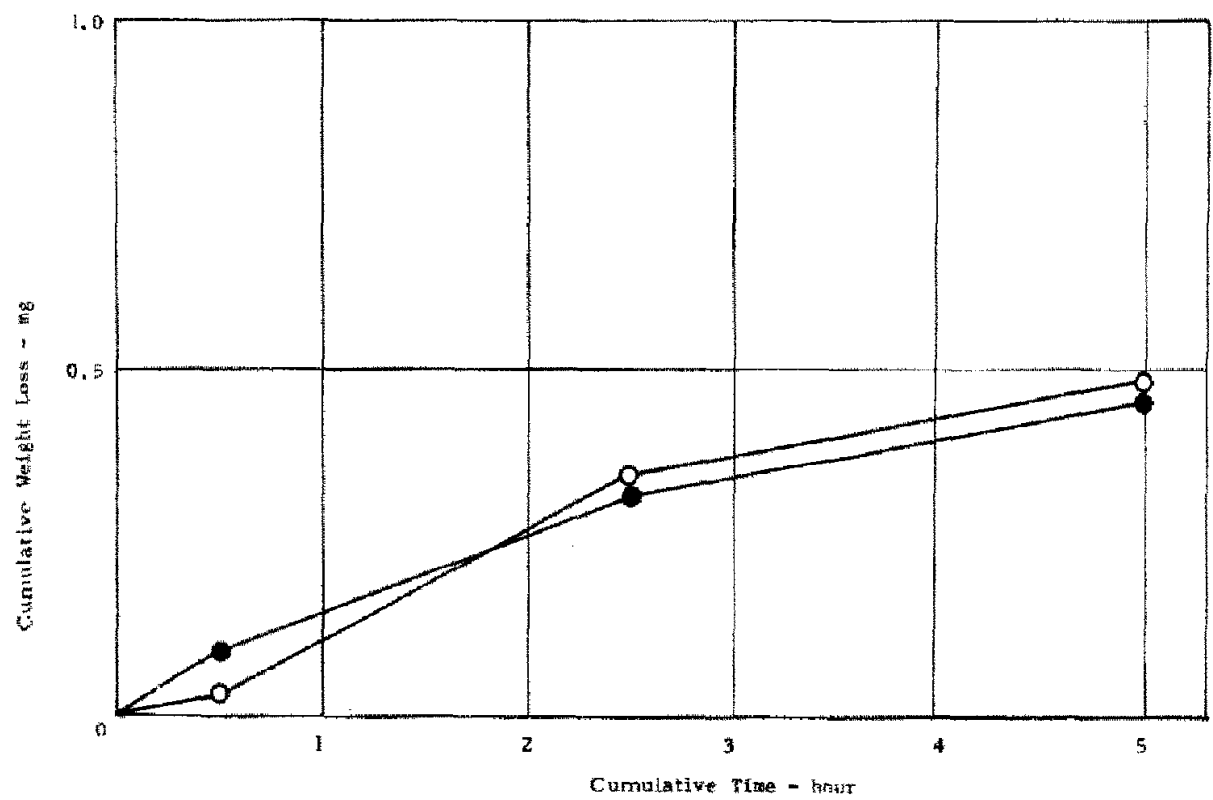

Fig. 7. Cumulative weight loss curves of different $(0,1) 1018$ carbon steel specimens in the Venturi tests (flow velocity, $49 \mathrm{~m} \mathrm{~s}^{-1}$ ).

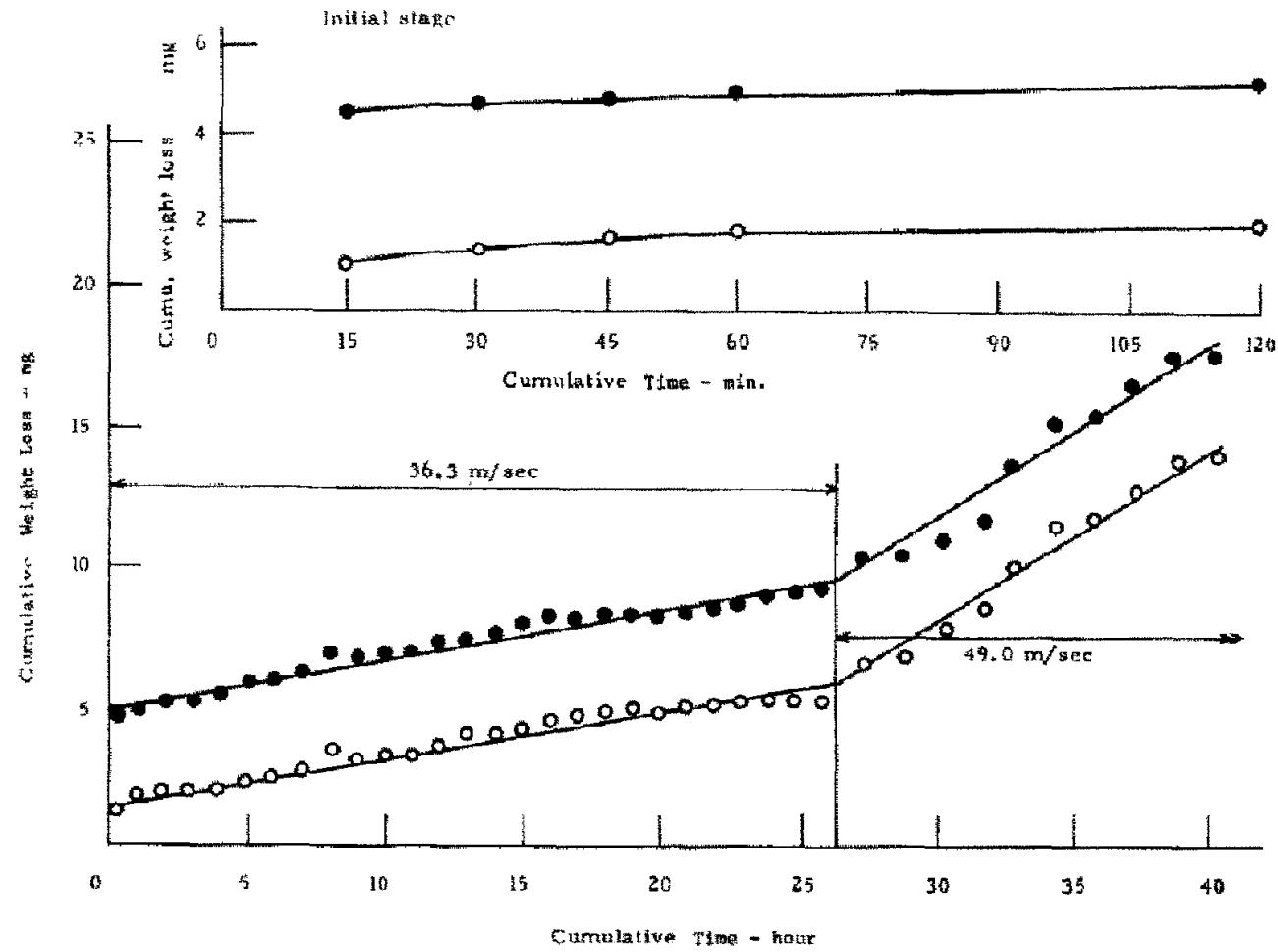

Fig. 8. Cumulative weight loss curves of different $(0, \bullet) 1100 \cdot 0$ aluminum specimens in the Venturi tests. 
TABLE 3

MDPR $_{\max }$ of 1018 carbon steel and $1100-0 \mathrm{Al}$ in Venturi and vibratory tests

\begin{tabular}{|c|c|c|c|c|}
\hline & \multicolumn{2}{|l|}{ Vibratory test } & \multirow{2}{*}{$\begin{array}{l}\text { Venturi test } \\
M D P R_{\max } \\
\left(\times 10^{-3} \text { in }^{-1}\right. \\
\left.\left(\mu \mathrm{m} \mathrm{h} \mathrm{h}^{-1}\right)\right)\end{array}$} & \multirow{2}{*}{$\alpha^{b}$} \\
\hline & $\begin{array}{l}\text { Amplitude } \\
\left(\times 10^{-3} \text { in }(\mu \mathrm{m})\right)\end{array}$ & $\begin{array}{l}M D P R_{\max } \\
\left(\times 10^{-3} \text { in h}^{-1}\left(\mu \mathrm{m} \mathrm{h}^{-1}\right)\right)\end{array}$ & & \\
\hline 1018 carbon steel & $\begin{array}{l}1.0(25.4) \\
2.0(50.8)\end{array}$ & $\begin{array}{l}0.21(5.33) \\
0.61(15.5)\end{array}$ & $\begin{array}{l}0.015^{c} \\
(0.38)\end{array}$ & $\begin{array}{l}14.0 \\
40.7\end{array}$ \\
\hline $1100-0 \mathrm{Al}$ & $\begin{array}{l}1.0(25.4) \\
1.5(38.1)\end{array}$ & $\begin{array}{l}5.1(130) \\
20.4(518)\end{array}$ & $\begin{array}{l}0.28 \\
(7.11)\end{array}$ & $\begin{array}{l}18.3 \\
73.8\end{array}$ \\
\hline
\end{tabular}

$49 \mathrm{~m} \mathrm{~s}^{-1}$

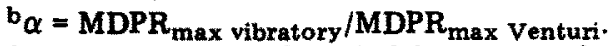

$c$ Mean value over $5 \mathrm{~h}$ period from start of test.

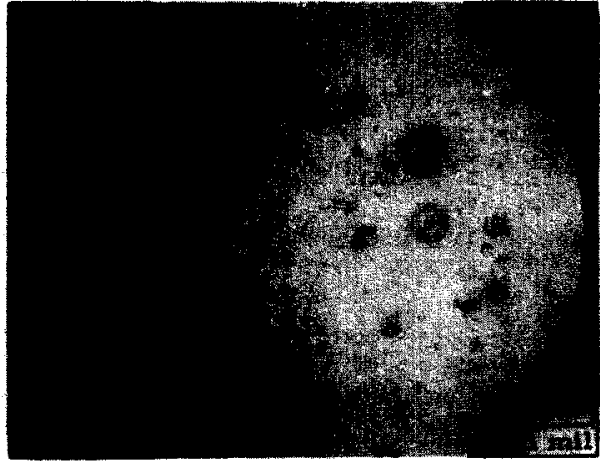

(a)

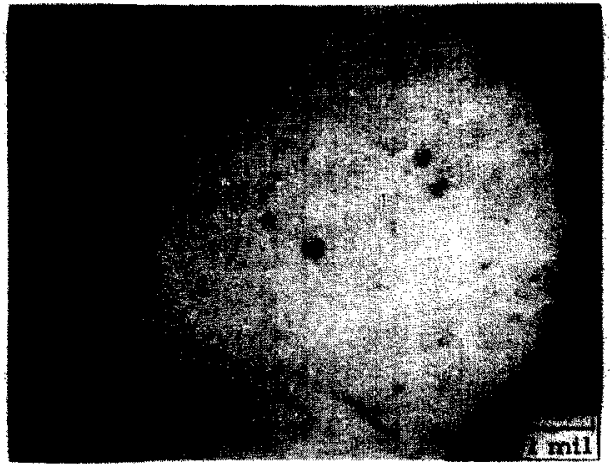

(b)

Fig. 9. Impact pits caused by bubble collapse: (a) vibratory test (amplitude, $1.5 \times 10^{-3}$ in; test duration, $15 \mathrm{~s}$ ); (b) Venturi test (flow velocity, $49 \mathrm{~m} \mathrm{~s}^{-1}$; test duration, $30 \mathrm{~min}$ ).

$$
a=\int_{P_{1}}^{\infty} n(P) \mathrm{d} P
$$

Equation (1) gives the total pit number and pulse densities for the various tests listed in Table 4.

When the collapse pressure $P_{i}$ occurs repeatedly, thare are $N\left(P_{i}\right)$ fatigue fracture cycles of the metal surface. When it is assumed that weight loss due to impact fracture is very small (material removal from the center of the pit) then the following formula for the weight loss during the stationary period in either facility can be derived from Miner's law:

$$
\alpha=\frac{\operatorname{MDPR}_{\max , \text { vibratory }}}{\operatorname{MDPR}_{\max , \text { venturi }}}=\frac{\sum_{P_{i}}^{\infty} n\left(P_{i}\right) / N\left(P_{i}\right)}{\sum_{P_{z}}^{\infty} n^{\prime}\left(P_{i}\right) / N\left(P_{i}\right)}
$$




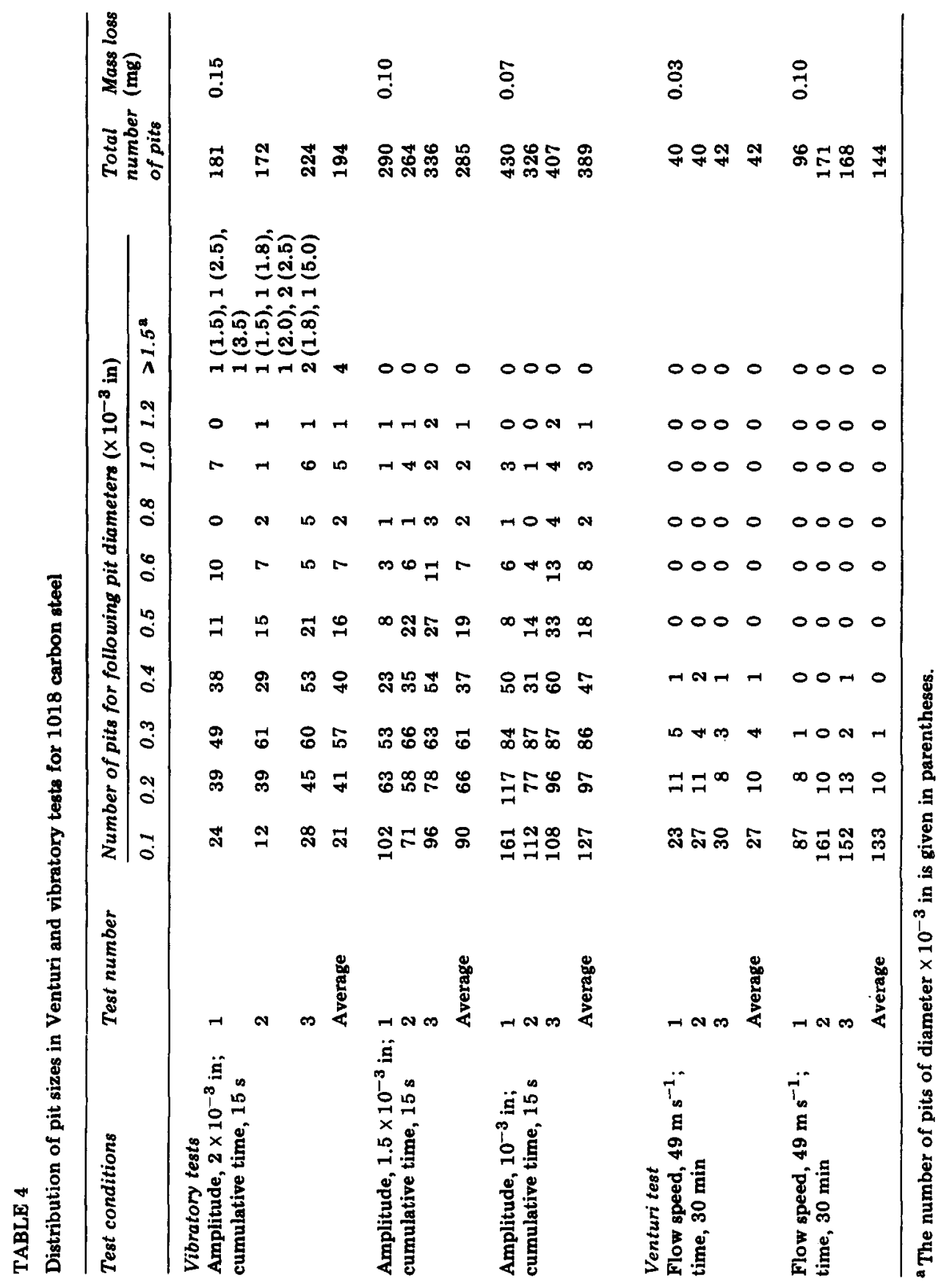




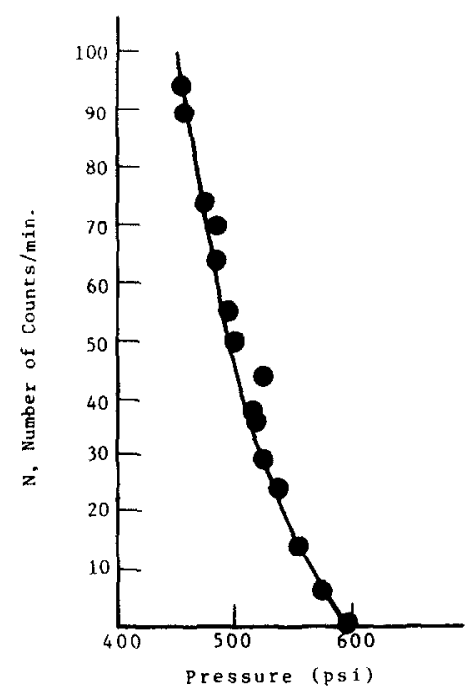

Fig. 10. Number of counts per minute us. pressure for a typical Venturi test (flow speed, $49 \mathrm{~m} \mathrm{~s}^{-1}$ ).

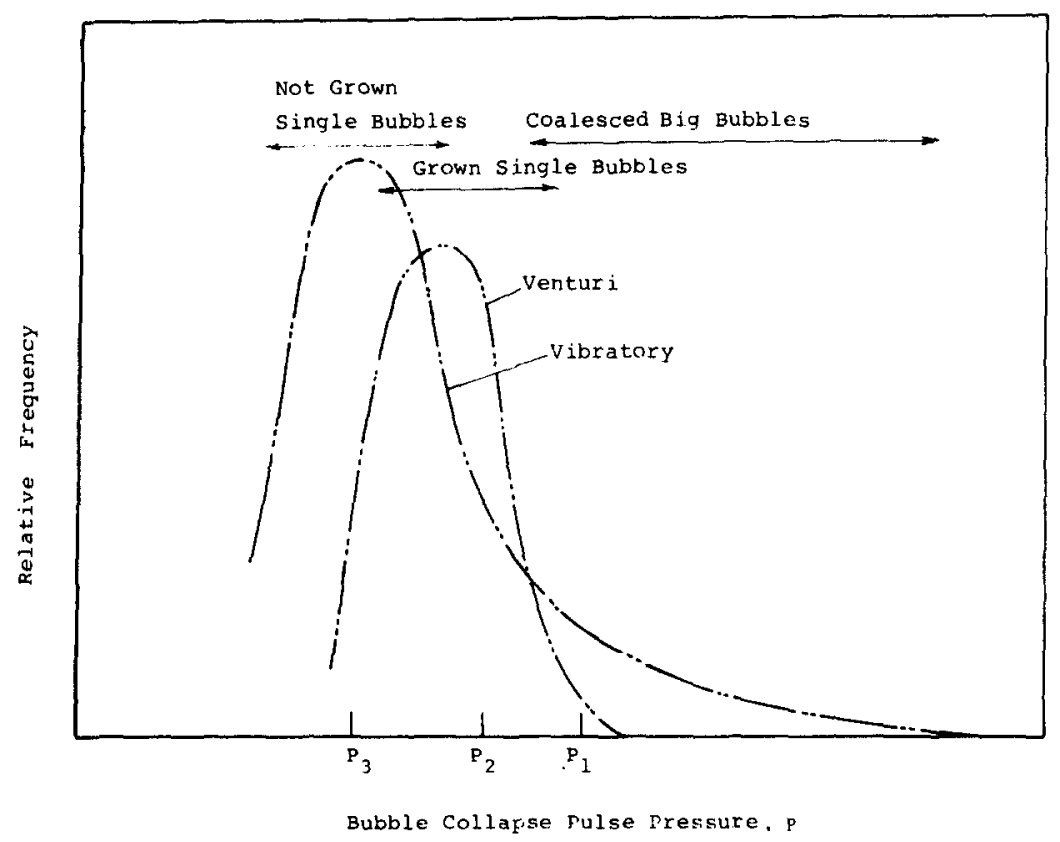

Fig. 11. Bubble collapse pressure distribution for Venturi and vibratory (postulated) facilities. 
or

$$
\alpha=\frac{\sum_{P_{3}}^{\infty} n\left(P_{i}\right) / N\left(P_{i}\right)}{\sum_{P_{3}}^{\infty} n\left(P_{i}\right) / N\left(P_{i}\right)}
$$

Equation (2) can easily explain the results of Table 3 which show that the difference in erosion rates between facilities is larger for 1100-0 Al than for the 1018 carbon steel.

Figure 12 shows the distribution of the erosion particle sizes for Japanese S15C carbon steel (similar to 1018 carbon steel and S55C carbon steel) during the stationary period tested in the vibratory facility at Fukui University [4]. Figure 13 shows particle sizes for neutron-irradiated 302 stainless steel (classified by filters) in the University of Michigan Venturi facility $[1,9]$. Large erosion particles (approximately $80 \mu \mathrm{m}$ in size) were observed during the stationary period, although $\mathrm{MDPR}_{\max }$ was very small. Comparing the results it is considered that the weight loss is small in the Venturi test because of the low bubble collapse pressure and the smaller number of bubbles, but a few fatigue cracks propagate deeply and form large erosion particles in some places.

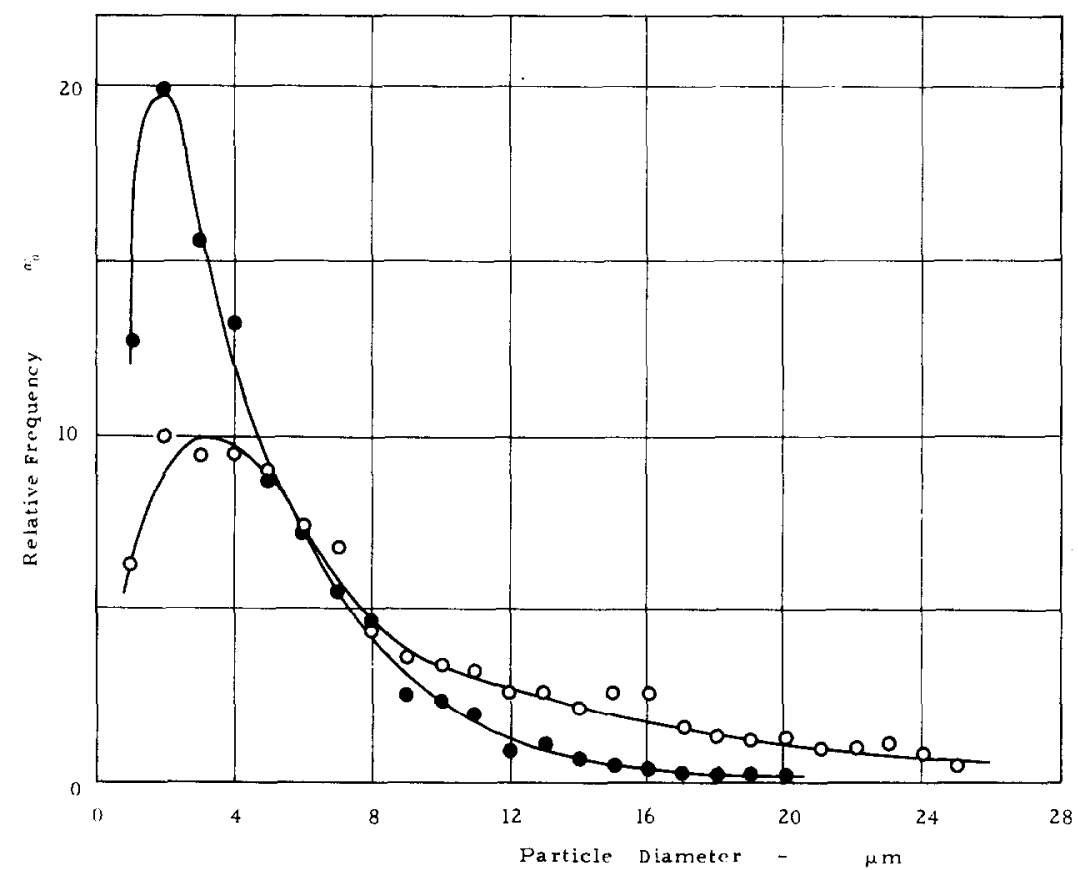

Fig. 12. Erosion particle size distribution which falls off between 60 and 90 min after start of vibratory test $\left(22.1 \mathrm{kHz}\right.$; ion-exchanged water; $\left.25^{\circ} \mathrm{C}\right): O, S 15 \mathrm{C}$ carbon steel, $\mathrm{MDPR}_{\max }=52 \mu \mathrm{m} \mathrm{h}^{-1}, 134 \mathrm{HV} ; \bullet, \mathrm{S} 55 \mathrm{C}$ carbon steel, $\mathrm{MDPR}_{\max }=6.2 \mu \mathrm{m} \mathrm{h}^{-1}$, $230 \mathrm{HV}$. 


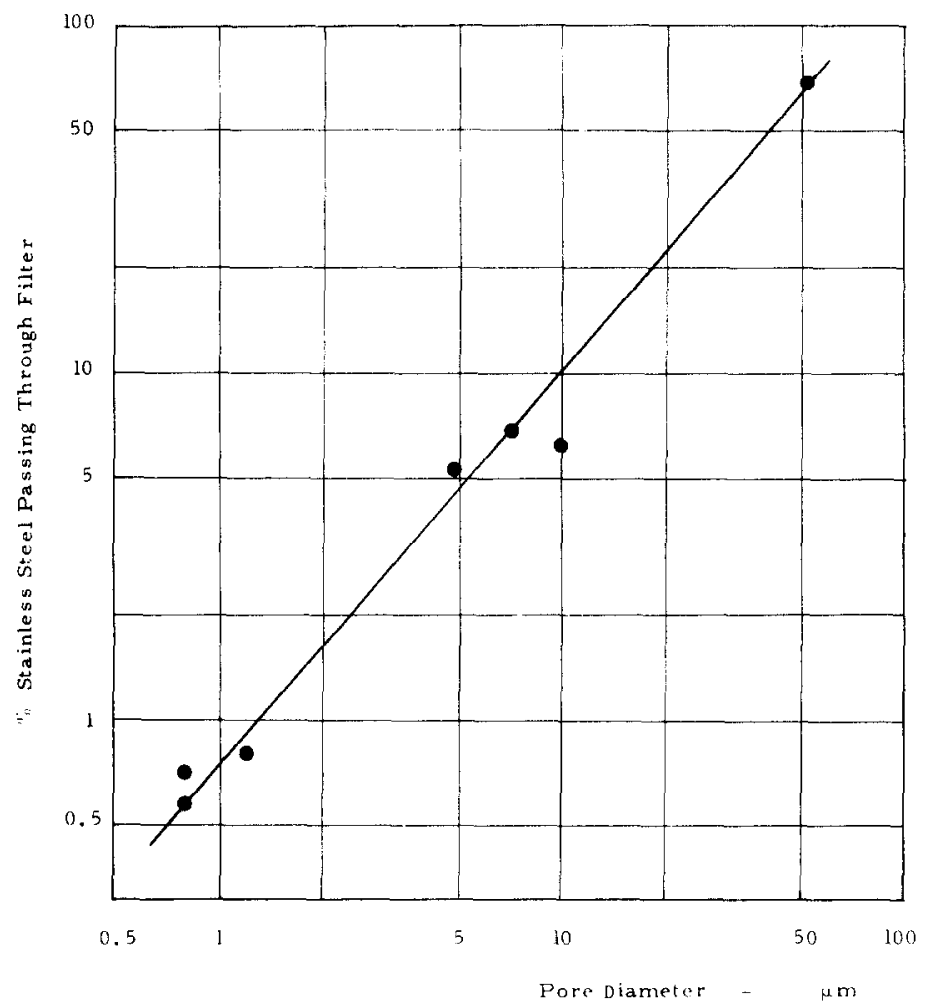

Fig. 13. Percentage of stainless steel passing through filter us. filter pore diameter for a Venturi test (flow velocity, $19.1 \mathrm{~m} \mathrm{~s}^{-1} ; \mathrm{MDPR}_{\max }=0.052 \mu \mathrm{m} \mathrm{h}^{-1}$; neutron-irradiated 302 stainless steel) [9].

\section{Conclusions}

The following conclusions are obtained from the discussions above.

(1) Each bubble in the Venturi test grows and collapses, often becoming much larger than most bubbles in the vibratory facility. Many bubbles in the vibratory test grow and collapse within a single horn cycle, thus remaining quite small [10]. However, some bubbles in the vibratory test may coalesce into bubbles larger than those generally found in the Venturi test, and these larger bubbles then collapse. Therefore a large collapse pressure may occur in the vibratory test, as indicated by the specimen surface observations reported here.

(2) Because even the collapse pressure of small bubbles in the vibratory test affects the 1100-0 Al specimens, the difference in the MDPR $\mathrm{max}_{\max }$ values of the Venturi test and vibratory test becomes larger for 1100-0 Al than for 1018 carbon steel which is a higher strength material.

(3) In the Venturi test a few cracks gradually propagate deeply inside and large erosion particles are formed in some places, although its MDPR ${ }_{\max }$ is relatively very small. 


\section{Acknowledgments}

Financial support for work at the University of Michigan was derived from Office of Naval Research Contract N00014-76-C-0697 and University of Michigan Work Study and Student Employment Program Funds.

\section{References}

1 W. J. Walsh and F. G. Hammitt, Cavitation and erosion damage and damage particlesize measurements with radioisotopes, Nucl. Sci. Eng., 14 (3) (1962) 217 - 222.

2 F. G. Hammitt, Cavitation damage and performance research facilities. In G. N. Wood (ed.), Proc. ASME Symp. on Cavitation Research Facilities and Techniques, American Society of Mechanical Engineers, New York, 1964, pp. $175-184$.

3 F. G. Hammitt and M. K. De, Cavitation erosion of aluminum considering bubble collapse, pulse height spectra and cavitation erosion efficiency, Proc. Int. Conf. on Wear of Materials, Dearborn, MI, April 16 - 18, 1979, in Wear, 55 (2) (1979) 221 234.

$4 \mathrm{~T}$. Okada, J. Iwamoto and K. Sano, Fundamental studies on cavitation erosion (observation of the eroded surface by scanning electron microscope), Bull. JSME. 20 (147) (1977) $1067-1075$.

5 F. G. Hammitt, T. D. Helmholdt and M. K. De, Erosion of soft aluminum in cavitating Venturi, Proc. ASME Cavitation and Polyphase Flow Forum, June 1979, American Society of Mechanical Engineers, New York, 1979, pp. 9 - 12.

6 R. Sato, S. Tamiya and H. Kato, Study on cavitation erosion, J. Soc. Naval Archit. Jpn., (134) (December 1973) 53 - 63 (in Japanese).

7 P. A. Lush and S. P. Hutton, The relation between cavitation intensity and noise in a Venturi-type section, Proc. Int. Conf. on Pump and Turbine Design and Development, 1 - 3 September, 1976, National Engineering Laboratory, East Kilbride, Glasgow, 1976, pp. $1-11$.

$8 \mathrm{~K}$. Endo, T. Okada and Y. Babb, Fundamental studies on cavitation erosion, Bull. JSME, 12 (52) (1969) 729 - 737.

9 F. G. Hammitt, Observations on cavitation damage in flowing systems, J. Basic Eng., 85 (3) (1963) $347-359$.

$10 \mathrm{H}$. G. Olson and F. G. Hammitt, High-speed photographic studies of ultrasonically induced cavitation, J. Acoust. Soc. Am., 45 (5) (1969) Part 2, $1272-1283$. 